\title{
Frog skin cultures secrete anti-yellow fever compounds
}

\author{
Carolina Muñoz-Camargo ${ }^{1}$, Margarita Correa Méndez ${ }^{1}$, Vivian Salazar ${ }^{1}$, Johanna Moscoso ${ }^{1}$, Diana Narváez ${ }^{1}$, \\ Maria Mercedes Torres ${ }^{1}$, Franz Kaston Florez ${ }^{2}$, Helena Groot ${ }^{1}$ and Eduardo Mitrani ${ }^{3}$
}

There is an urgent need to develop novel antimicrobial substances. Antimicrobial peptides (AMPs) are considered as promising candidates for future therapeutic use. Because of the re-emergence of the Flavivirus infection, and particularly the yellow fever virus (YFV), we have compared the antiviral activities from skin secretions of seven different frog species against YFV (strain 17D). Secretions from Sphaenorhynchus lacteus, Cryptobatrachus boulongeri and Leptodactylus fuscus displayed the more powerful activities. S. lacteus was found to inhibit viral lysis of Vero E6 cells even at the highest viral concentration evaluated of $10 \mathrm{LD}_{50}$. We also report the identification of a novel frenatin-related peptide from $S$. lacteus and found that this peptide-on its own-can lead to $35 \%$ protection against YVF, while displaying no cytotoxicity against somatic cells even at fivefold higher concentrations. These results are attractive and support the need for continued exploration of new sources of AMPs from frog skin secretions such as those described here in the development of new compounds for the treatment of infectious diseases in general and specific viral infections in particular.

The Journal of Antibiotics (2016) 69, 783-790; doi:10.1038/ja.2016.16; published online 6 April 2016

\section{INTRODUCTION}

Skin secretions of advanced frogs (suborder: Neobatrachia) are by far the most important source of antimicrobial peptides (AMPs) with several of peptide antibiotics found in different frog species. ${ }^{1}$ These secretions not only produce large amounts of biologically active peptides that are similar to mammalian neuropeptides and hormones, but also contain a rich arsenal of broad-spectrum cytolytic AMPs., ${ }^{2,3}$ Amphibian AMPs have typical features like short length of amino-acid residues (11-46), an amphipathic structure ( $\alpha$-helix) and a cationic charge. ${ }^{4}$ These features have an important role in the antimicrobial activity and have been effective against bacteria, ${ }^{5,6}$ fungi ${ }^{7,8}$ and viruses. $^{9-11}$

The yellow fever virus (YFV) is a member of the Flaviviridae family that has re-emerged with a large number of infections worldwide. ${ }^{12}$ This disease was recently described among one of the most lethal viral diseases for which no approved antiviral therapy has yet been discovered. ${ }^{13}$ Infections with YFV cause a severe febrile disease with hemorrhage, multi-organ failure and shock, with a mortality rate up to $50 \% .^{14,15}$ YFV is a zoonotic agent: even though there is a safe and efficient vaccine available, the virus is reintroduced from animal reservoirs into human populations. ${ }^{16}$ South America and Sub-Saharan Africa are endemic regions with an estimated number of 200000 reported cases per year. ${ }^{17}$ Moreover, the recent increase in the density and distribution of the urban mosquito vector, Aedes aegypti, has raised the risk of infection and spread of YFV. ${ }^{16,18}$

On the basis of the above considerations, we have evaluated the anti-YFV activities of the skin secretions from seven frog species and their cytotoxicity. We found that secretions from S. lacteus, C. boulengeri and L. fuscus have the most potent activity against YFV infection in Vero cells. In S. lacteus secretions, we used rapid amplification (RACE)-PCR and degenerate primers, to elucidate the sequence of a novel frenatin-related AMP. We further show that this newly identified AMP can display_on its own-moderate cellular protection against YFV-infected Vero cells without causing significant cytotoxicity, even at high peptide concentration.

\section{MATERIALS AND METHODS}

Frog skin micro-organs and secretions

We used the skin secretions from different frogs collected around Colombia. These regions include the Guajira, the upper Magdalena Valley, the Amazon region and the Andean piedmont. The selected species were Sphaenorhynchus lacteus, Cryptobatrachus boulengeri, Leptodactylus fuscus, Pristimantis medemi, Trachycephalus venulosus, Hypsiboas lanciformis and Hypsiboas fasciatus. All procedures were adhered to the license No. 2 of the 20th of January 2009, and realized according to the access to genetic resources contract $N^{\circ} 26$ of 2009 from the Ministerio de Medio Ambiente, Colombia.

The technique used to obtain frog skin micro-organs (SMOs) and frog skin in vitro secretions, denominated as conditioned media (CM), was obtained by culturing the SMOs in serum-free media for $24 \mathrm{~h}$ as described previously. ${ }^{19}$ Total protein concentration from each CM culture ranged from 300 to $600 \mu \mathrm{g} \mathrm{ml}^{-1}$. It was determined using the peptide bradykinin standard curve (RPPGFSPFR) (Sigma Chemical, Houston, TX, USA). ${ }^{20} \mathrm{CM}$ was tested at various concentrations ranging from $50 \%$ diluted with equal volume of serumfree culture media to $5 \% \mathrm{CM}$ obtained by diluting the CM with $95 \%$ serumfree media.

\footnotetext{
${ }^{1}$ Laboratory of Human Genetics, Department of Biological Sciences, Universidad de los Andes, Bogotá, Colombia; ${ }^{2}$ Fundación Nativa, Bogotá, Colombia and ${ }^{3}$ Institute of Life Sciences, Hebrew University of Jerusalem, Givat Ram, Jerusalem, Israel

Correspondence: H Groot, Laboratory of Human Genetics, Department of Biological Sciences, Universidad de los Andes, Cr. 1 № 18A-10 Building M1- 2 floor, Bogotá 110321, Colombia.

E-mail: hgroot@uniandes.edu.co

Received 20 May 2015; revised 11 January 2016; accepted 20 January 2016; published online 6 April 2016
} 


\section{Molecular cloning of cDNAs by $3^{\prime} \mathrm{RACE}$ that may encode AMPs} Total RNA was extracted from five S. lacteus SMOs after 2 days in culture by TRIzol Reagent (Invitrogen, Carlsbad, CA, USA) as described previously. ${ }^{21}$ cDNA was synthesized by SMART Techniques using the SMART RACE cDNA Amplification Kit (Clontech, Palo Alto, CA, USA), according to the manufacturer's protocol. The $3^{\prime}$ RACE reactions employed a UPM primer (supplied with the kit) and a degenerate sense primer S1 (5'ACTTTC YGAWTTRYAAGMSCARABATG3') that was designed previously. ${ }^{22}$

cDNAs from Phyllomedusa species. The PCR was performed under the following conditions: $97^{\circ} \mathrm{C}$ for $7 \mathrm{~min}$; followed by 35 cycles at $95^{\circ} \mathrm{C}$ for $45 \mathrm{~s}$, $52^{\circ} \mathrm{C}$ for $30 \mathrm{~s}$ and $72{ }^{\circ} \mathrm{C}$ for $30 \mathrm{~s}$ and a final extension at $72^{\circ} \mathrm{C}$ for $10 \mathrm{~min}$. The PCR products were cloned into the $\mathrm{pGEM}^{\infty}$-T Easy Vector System (Promega, Madison, WI, USA) using standard procedures. E. coli white positive colonies were screened with M13 primers (Forward 5'-d(CGCCAGGGTTT TCCCAGTCACGAC)-3', Reverse 5'-d(TCACACAGGAAACAGCTATGAC)-3'). Amplification products of the expected sizes (400-500 base pairs) were sequenced by the Applied Biosystems Genetic Analyzer (ABI PRISM 3500, CA, USA). We used the program BLASTn (Smith-Waterman) ${ }^{23}$ from the National Center for Biotechnology (NCBI) and the ClustalW2 ${ }^{24}$ alignment program from The European Bioinformatics Institute (EMBL-EBI) to analyze the sequences obtained.

\section{Peptide synthesis}

The frenatin 2.3S peptide (F2.3S GLVGTLLGHIGKILGG) described in this study was synthesized by solid phase supplied by GL Biochem (Shanghai, China). The crude synthetic peptide was purified on a Venusil XBP-C18 RP-HPLC column $(4.6 \mathrm{~mm} \times 250 \mathrm{~mm})$, eluting at a flow rate of $1 \mathrm{ml}$ per minute by a linear gradient of acetonitrile in $0.1 \%$ trifluoroacetic acid in water by reversed-phase HPLC. The purity $(>98 \%)$ and identity of the synthetic peptide was confirmed by electrospray MS.

\section{Cell culture and YFV stocks}

The cell lines used to test the cytotoxicity of the CMs cultures were Chinese hamster (Cricetulus griseus) ovary cells (CHO-K1 ATCC CCL-61) and African monkey (Cercopithecus aethiops) kidney cells (Vero E6 cell line ATCC CRL-1586). The CHO-K1 cell line was grown as a monolayer culture in Roswell Park Memorial Institute medium (RPMI-1640) and Vero E6 cell line in Dubelcco's Modified Eagle Medium (DMEM). Both media were supplemented with $10 \%$ FBS, penicillin $\left(1000 \mathrm{IU} \mathrm{ml}^{-1}\right)$, streptomycin $\left(1000 \mathrm{IU} \mathrm{ml}^{-1}\right)$ and fungizone $\left(1 \mu \mathrm{g} \mathrm{ml}^{-1}\right.$ amphothericin $\left.\mathrm{B}\right)$. Both were maintained at $37^{\circ} \mathrm{C}$ in a humidified $5 \% \mathrm{CO}_{2}$ atmosphere.

Vaccine strain 17D (Stamaril, Pasteur Merieux, Connaught, Lyon, France) was used as a source of YFV, which has been previously used to study alternative treatments of yellow fever infections. ${ }^{25}$ This vaccine contains 1000 mouse $\mathrm{LD}_{50}$ (lethal dose at which $50 \%$ of the subjects will die due to viral infection) viral units and was adjusted at $0.1 \mathrm{LD}_{50}, 1 \mathrm{LD}_{50}$ and $10 \mathrm{LD}_{50}$, diluted in DMEM non-supplemented.

\section{MTT assay}

Citotoxicity assay. Cell monolayers were trypsinized, washed with culture medium and plated in flat-bottomed 96-well microtiter trays with $3 \times 10^{5}$ cells per $\mathrm{ml}$ for CHO-K1 cells. After $24 \mathrm{~h}$ incubation, each diluted $\mathrm{CM}$ was added to the appropriate wells and the plates were incubated for $48 \mathrm{~h}$ at $37^{\circ} \mathrm{C}$ in a humidified incubator with $5 \% \mathrm{CO}_{2}$. The supernatants were removed from the wells, and cell viability was evaluated using the MTT technique described below for the antiviral colorimetric assay.

The percentage of viable treated cells was calculated in relation to untreated controls (viability percentage $=$ treated cells $\mathrm{OD} /$ untreated cells $\mathrm{OD} \times 100 \%$ ).

YFV infection and antiviral colorimetric assay. The infectivity of the 17D strain over the Vero E6 cell line $\left(3 \times 10^{5}\right.$ cells per $\left.\mathrm{ml}\right)$ was evaluated in a 6 - day time interval. ${ }^{25}$ Confluent Vero E6 cells in flat-bottomed, 96-well microtiter trays were infected with YFV (vaccine) strain $17 \mathrm{D}$ at $0.1 \mathrm{LD}_{50}, 1 \mathrm{LD}_{50}$ and $10 \mathrm{LD}_{50}$, and incubated at $37^{\circ} \mathrm{C}$ in humidified $5 \% \mathrm{CO}_{2}$. Cell viability was measured daily by the MTT colorimetric technique (3-(4,5-dimethylthiazol-2-yl)-2,5-diphenyltetrazolium bromide). ${ }^{26}$ Briefly, the supernatants were removed from the wells and $10 \mu \mathrm{l}$ of MTT (Sigma) (5 $\mathrm{mg} \mathrm{ml}^{-1}$ in PBS) was added to each well. The plates were incubated for $2 \mathrm{~h}$ at $37^{\circ} \mathrm{C}$, and $70 \mu \mathrm{l}$ of DMSO was added to the wells to dissolve de MTT crystals. The plates were placed on a shaker for $15 \mathrm{~min}$, and the optical density was determined at $595 \mathrm{~nm}\left(\mathrm{OD}_{595}\right)$ on a microplate absorbance spectrophotometer (Bio-Rad, Philadelphia, PA, USA).

The antiviral assay was performed using confluent Vero E6 cell monolayers in flat-bottomed 96-well microtiter trays. Three dilutions of frog skin secretions (CMs) were prepared (at 5, 25 and 50\%) and were added $1 \mathrm{~h}$ before viral infection. Three viral concentrations $\left(0.1 \mathrm{LD}_{50}, 1 \mathrm{LD}_{50}\right.$ and $\left.10 \mathrm{LD}_{50}\right)$ were used, and these samples were incubated at $37^{\circ} \mathrm{C}$ in a humidified $5 \% \mathrm{CO}_{2}$ atmosphere. To determine the antiviral activity of the F 2.3S, confluent Vero E6 cell monolayers were first exposed to twofold serial dilutions (from $20 \mu \mathrm{g} \mathrm{ml}^{-1}$ ) of this peptide. In this assay, we used the high viral YFV concentration $10 \mathrm{LD}_{50}$ and incubation conditions as described above. Controls consisted of untreated infected, treated uninfected and untreated uninfected cells. Finally, cell viability was evaluated by MTT as described above.

The $50 \%$ cytotoxic concentration $\left(\mathrm{CC}_{50}\right)$ of the test $\mathrm{CMs}$ is defined as the concentration that reduces the $\mathrm{OD}_{595}$ of treated uninfected cells to $50 \%$ of untreated uninfected cells. The 50\% antiviral effective concentration, i.e., $50 \%$ inhibitory concentration of the viral effect $\left(\mathrm{IC}_{50}\right)$, is expressed as the concentration that achieves $50 \%$ protection of treated infected cells from YFV induced destruction.

The percent protection was calculated by the following formula:

$[(\mathrm{A}-\mathrm{B}) / \mathrm{C}-\mathrm{B}) \times 100]$

where $\mathrm{A}$ is the absorbance of the test sample, $\mathrm{B}$ is the absorbance of the virus-infected control (no compound) and $\mathrm{C}$ is the absorbance of untreated uninfected cells, and it is expressed as ' $\%$ of control'. ${ }^{26}$

\section{Data analysis}

All results were represented as means \pm s.d. of three replicates. Differences among data were determined by one-way analysis of variance (ANOVA) followed by Tukey and Dunnett's test. Data were considered statistically significant at a $\mathrm{P}$-value $<0.05$.

\section{RESULTS}

Frog skin in vitro secretions were obtained by culturing frog SMOs in serum-free media, for $24 \mathrm{~h}$ and collecting the $\mathrm{CM}$ as described previously. ${ }^{19}$

\section{Cytotoxicity of frog skin secretions in $\mathrm{CHO}-\mathrm{K} 1$ cell line}

All evaluated CMs were not cytotoxic to the $\mathrm{CHO}-\mathrm{K} 1$ cell line (Figure 1). $\mathrm{CM}$ from $H$. fasciatus was not toxic and moreover, was found to stimulate the growth of the $\mathrm{CHO}-\mathrm{K} 1$ cells even at the highest concentration tested of $50 \% \mathrm{CM}$.

\section{YFV infectivity on Vero E6 cell line}

The infectivity of YFV was evaluated at three concentrations $\left(0.1 \mathrm{LD}_{50}\right.$, $1 \mathrm{LD}_{50}$ and $10 \mathrm{LD}_{50}$ ) on the Vero E6 cell line. All doses tested showed a marked cell death after 6 days (Figure 2), as a consequence of maximal viral infectivity in agreement with previous reports. ${ }^{27}$

\section{Frog skin secretions protect Vero E6 cells from viral infection and death}

As can be seen in Figures 3a and b, highly potent inhibition of YFV infection was observed even at the highest viral concentration tested of $10 \mathrm{LD}_{50}$. In particular when infected cells were treated with $50 \%$ of $\mathrm{CM}$ from $S$. lacteus and C. boulengeri. These CMs also had a protective effect on Vero E6 cells viability in the presence of $0.1 \mathrm{LD}_{50}$ and $1 \mathrm{LD}_{50}$ YFV even at the lowest CM concentrations tested (5\%). Similar results were observed when cells were infected and treated with CMs from L. fuscus (Figure 3c). However, the protective effect was lower compared with CM from S. lacteus and C. boulengeri. 


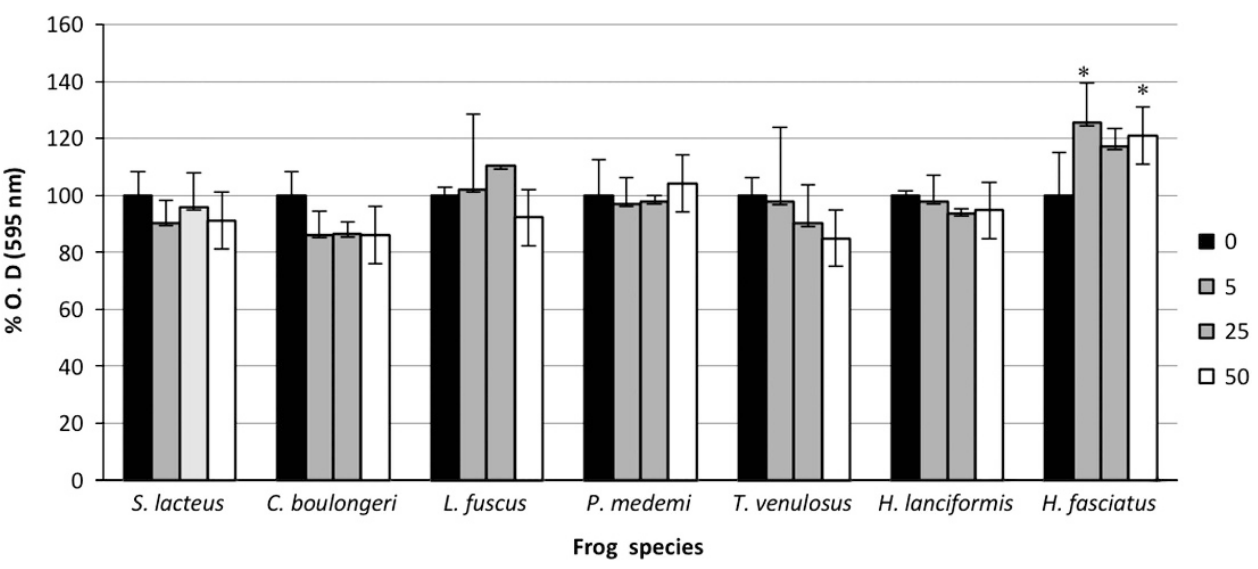

Figure 1 Cytotoxic effect of frog skin secretions (CMs 5, 25 and 50\%) from seven species in CHO-K1 cell line. Results are reported as percentage of untreated controls. The data are presented as the mean of three replicate samples. ANOVA ${ }^{*} P$-value $<0.05$.

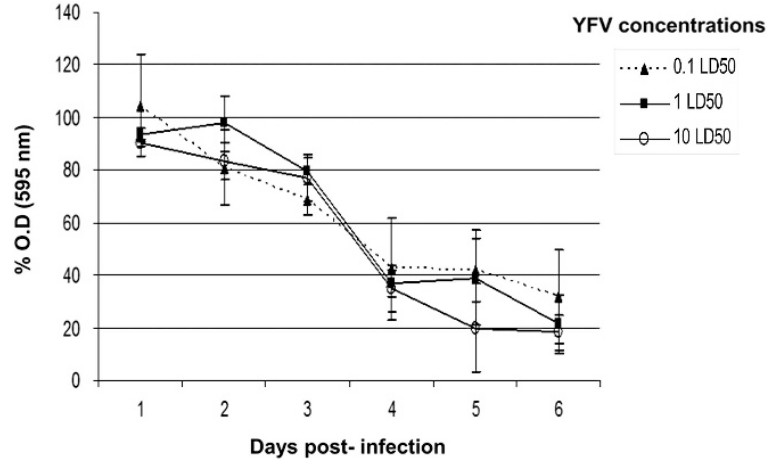

Figure 2 Vero E6 cell viability after the infection with three viral doses: 0.1 $\mathrm{LD}_{50}, 1 \mathrm{LD}_{50}$ and $10 \mathrm{LD}_{50}$ over a period of 6 days. Dunnett's test indicated significant differences ( ${ }^{*} P$-value $<0.05$ ) between each treatment in relation to control.

The other CMs evaluated (H. fasciatus, P. medemi, H. lanciformis and T. venulosus) were less effective against YFV infection. Nevertheless, significant antiviral activity was also detected (Figures $4 \mathrm{a}$ and $\mathrm{d}$ ).

The first panel of Figures $3 \mathrm{a}-\mathrm{c}$ and $4 \mathrm{a}-\mathrm{d}$ shows the cytotoxic effect of different CMs on Vero E6 cells. Six out of seven CMs were found to be not cytotoxic. Only $\mathrm{CM}$ from $T$. venulosus at the highest concentration tested $(50 \%)$ was found to display slight toxicity on Vero E6 cells.

Frenatin 2.3S derived from S. lacteus has anti-YFV activity

Encouraged by the anti-YFV results observed with secretions from S. lacteus CM, we have attempted to characterize the composition of the AMPs present in these frog skin secretions. To that extent, we have used a reverse genetics approach using degenerate primers based on conserved sequences of several AMPs secreted by Phyllomedusa, ${ }^{22}$ as described in Materials and Methods section. Several clones were isolated and three clones were selected for sequencing (Sl-5, Sl-11 and Sl-16). The three clones were found to code for the same AMP precursor (Figure 5).

The cDNA sequence is 317-bp long with an open reading frame (ORF) that encodes a peptide of 71 amino-acid residues in length. A BLASTn search in the Genbank Database revealed that our sequence has the characteristic structure of anuran AMP precursors containing a putative signal peptide, an N-terminal acidic spacer domain, a Lys-Arg
(K-R) processing site and the mature AMP at the C-terminus. The signal peptide was identical in structure to frenatin 1.1 from Litoria infrafrenata, ${ }^{28}$ but it shows differences in the region localized on the acidic spacer domain and also in the frenatin encoding regions. Alignments of both full-length nucleic acid sequences (Figure 6) made using the ClustalW software revealed that preprofrenatin exhibited an identity of $66.7 \%$ at the amino-acid level. The new sequence was deposited in the database on 2012 (Accession no. AGB51284.1) and was confirmed and further characterized by Conlon et al. ${ }^{5}$

To test the antiviral activity of the newly found AMP, we synthesized the peptide based on the previously characterized F $2.3 \mathrm{~S}$ as described in Materials and Methods section. Figure 7a shows that at a concentration of $20 \mu \mathrm{g} \mathrm{ml}^{-1}$ has a 35\% protective effect in Vero E6 cells infected with YFV $\left(10 \mathrm{LD}_{50}\right)$. It should be noted that this peptide was also tested and found not to be cytotoxic at $100 \mu \mathrm{g} \mathrm{ml}^{-1}$ to Vero E6 cells as shown in Figure 7b.

\section{DISCUSSION}

In recent years, the Flavivirus genus has gained further attention due to re-emergence and increasing incidence of YFV, Dengue and others member of this group. ${ }^{16}$ Infections with YFV are a global public health problem and there is an urgent necessity of more potent and safe antivirals. For this reason, our 'biorational approach'29 is based on chemical prospecting which uses clues from amphibian physiology and its interaction with the environment. The physiological structure of the skin of these organisms and their exposure to such varied habitats with high microbial load is the reason why they are considered as an interesting model in the search of AMPs with possible medical and biotechnological significance.

In the present study, we evaluated frog skin secretions (CMs) from seven species against YFV. The results showed that the secretions from S. lacteus, C. boulongery and L. fuscus presented the best antiviral activity (Figure 3). We found that the frog skin secretions from S. lacteus had potent anti-YFV activity. We have also first identified the complete precursor of F2.3S from SMOs of S. lacteus after 2 days in culture, which was deposited in the GenBank accession no. AGB51284.1 and was then confirmed and characterized by Conlon et al. ${ }^{5}$ This AMP is highly related in the signal peptide region to the previous reported frenatin 1.1 from Litoria infrafrenata (Hylidae, Pelodryadinae), but shows limited similarity with the mature peptide ${ }^{28}$ and also with frenatin 2D from Discoglossus sardus (Alyti-dae). ${ }^{30}$ 

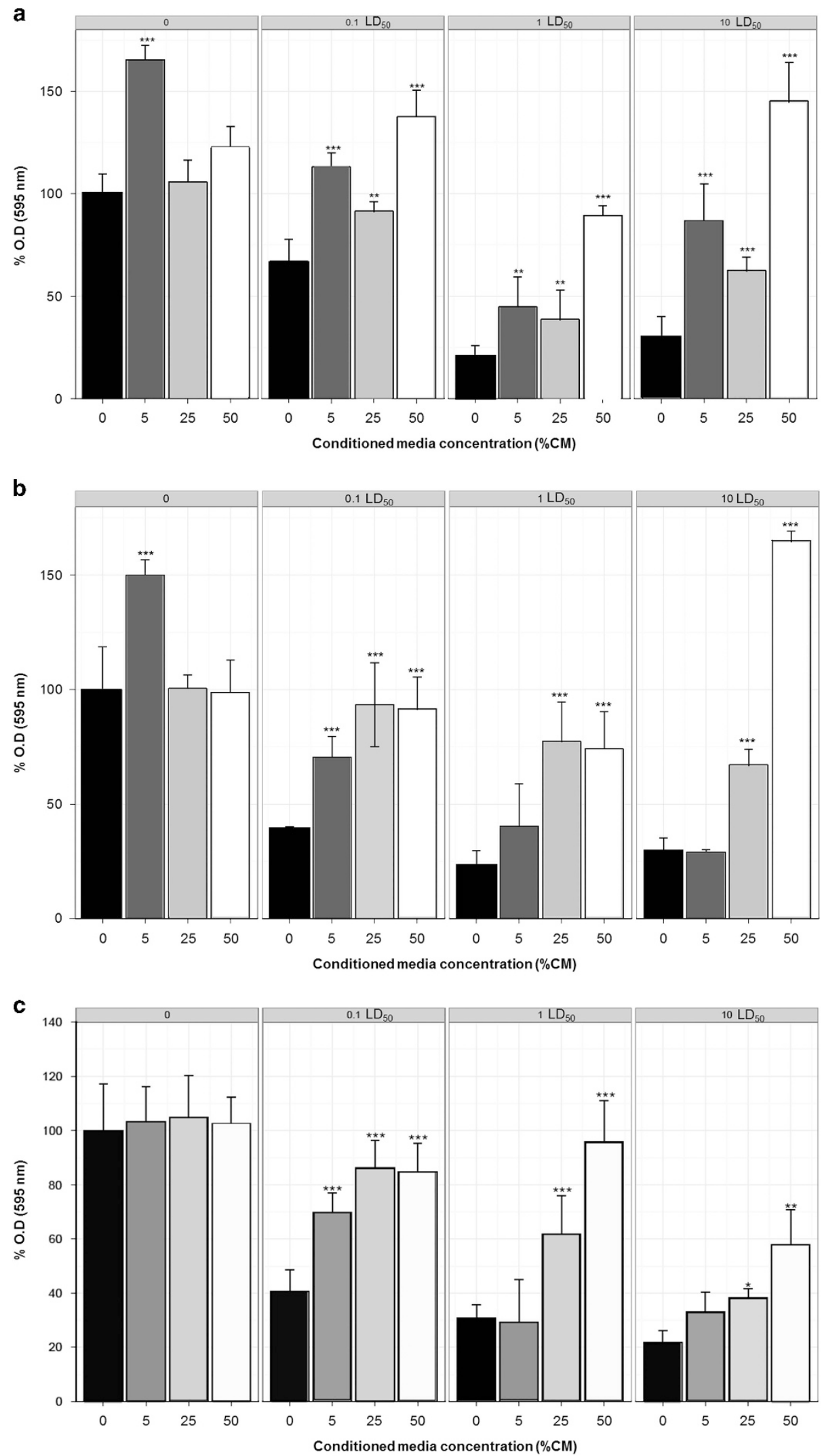

Figure 3 Potent anti-YFV activity of conditioned media (CM) from (a) Sphaenorhynchus lacteus, (b) Criptobatrachus boulengeri and (c) Leptodactylus fuscus on Vero E6 cells. First panel: cytotoxic effect in Vero E6 cells of the CMs at different concentrations (5, 25 and $50 \%$ ). The other three panels show Vero E6 cells exposed to three concentrations of YFV $\left(0.1 \mathrm{LD}_{50}, 1 \mathrm{LD}_{50}\right.$ and $\left.10 \mathrm{LD}_{50}\right)$ treated with 5,25 and $50 \%$ of $\mathrm{CM}$. Tukey test ${ }^{*} P$-value $<0.05$, ${ }^{* *} P$-value $<0.01,{ }^{* * *} P$-value $<0.001$ 
We here further show that this F $2.3 \mathrm{~S}$ has moderate anti-YFV cell protective (35\%) activity at the high concentration of $20 \mu \mathrm{g} \mathrm{ml}^{-1}$. The fact that total CM from S. lacteus has a much potent activity is not unexpected since most likely — as discussed previously ${ }^{19}$ — antimicrobial activity secreted by skin of amphibians is unlikely to be caused by a single peptide. ${ }^{31}$ Experiments are in progress to determine the sequence of other novel AMPs present in the active CMs using LC MS/MS analysis.

Although there are no reports of frog AMPs against YFV or other flaviviruses, there are relevant amphibian AMPs with antiviral properties, like Magainin-1 and 2 (Xenopus laevis) ${ }^{32}$ and Dermaseptin S1-S5 (Phyllomedusa sauvagei), which have activity against herpes simplex virus type 1 and type $2,{ }^{9}$ and caerin 1.1 , caerin 1.9 and maculatin 1.1 from different species of Australian tree frogs which inhibit HIV infection. ${ }^{11}$ In addition, other authors ${ }^{16}$ found that ivermectin, a broadly used anti-helminthic drug, presents a potent anti-YFV activity; however, it looses effectiveness against others flaviviruses. Given this, the synergism of this drug with AMPs would be an interesting form to potentiate the antiviral effect of both compounds. Recently, there have been reports of proinflammatory and immunomodulatory properties from $S$. lacteus frenatins, included F $2.3 S^{5}$ in response to bacterial infections. For this reason, we speculate that F2.3S could activate the signal pathway to recognize and regulate a viral infection response. ${ }^{33}$ In this regard, AMPs exert broad-spectrum antimicrobial activity, apart from many other potential roles in innate immunity, and represent a promising class of antiviral agents including both enveloped and non-enveloped viruses. ${ }^{34}$ Recent advances in understanding the mechanisms of their antiviral action(s) indicate that they have a dual role in antiviral defense, acting not only directly on the virion but also on the host cell. ${ }^{34}$
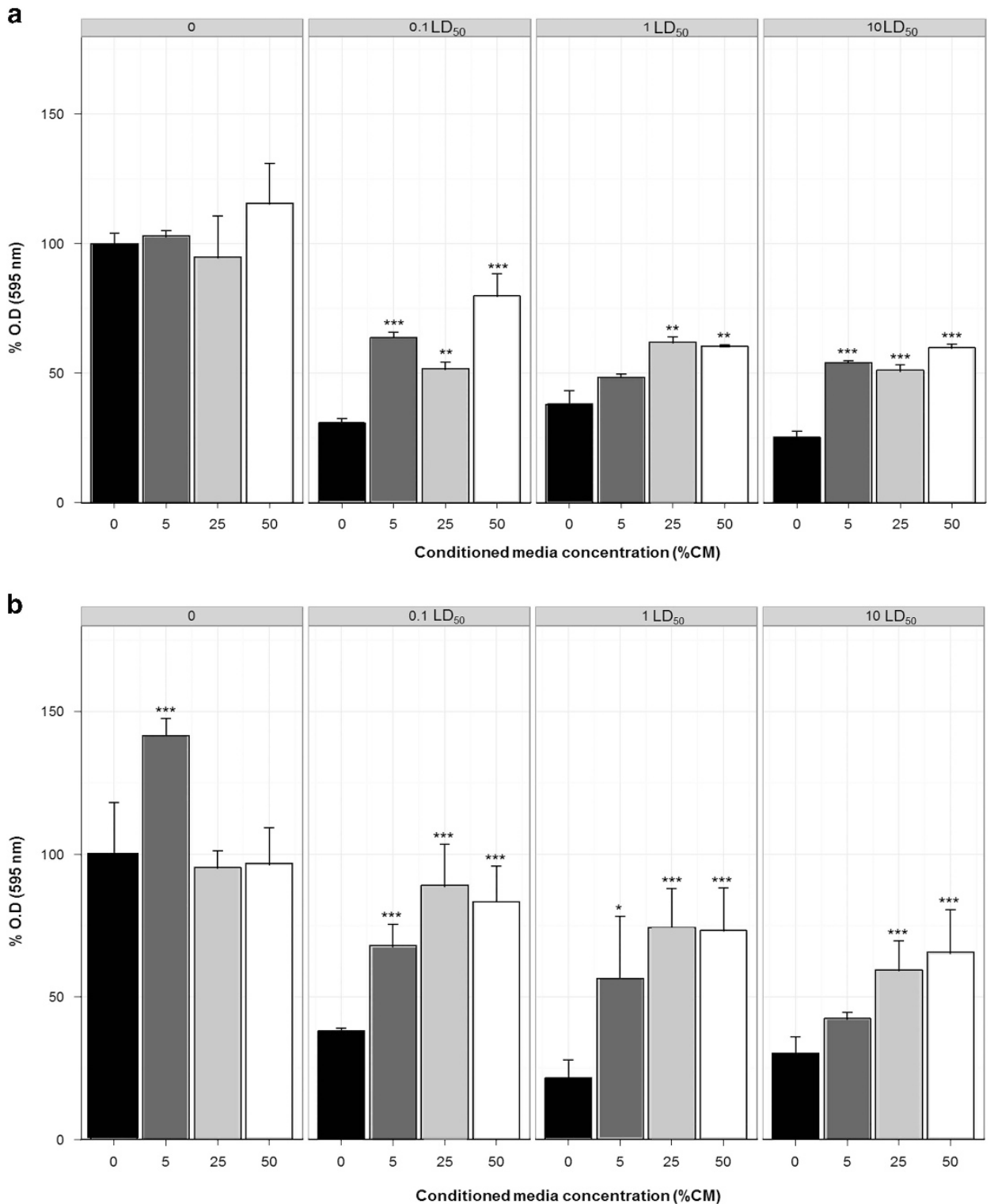

Figure 4 Moderate anti-YFV activity of conditioned media (CM) from (a) Hypsiboas fasciatus, (b) Pristimantis medemi, (c) Hypsiboas lanciformis and (d) Trachycephalus venulosus on Vero E6 cells. First panel: cytotoxic effect in Vero E6 cells of the CMs at different concentrations (5, 25 and 50\%). The other three panels show Vero E6 cells exposed to three concentrations of YFV $\left(0.1 L_{50}, 1 L_{50}\right.$ and $\left.10 L_{50}\right)$ treated with 5,25 and $50 \%$ of CM. Tukey test ${ }^{*} P$-value $<0.05,{ }^{* *} P$-value $<0.01,{ }^{* * *} P$-value $<0.001$ 

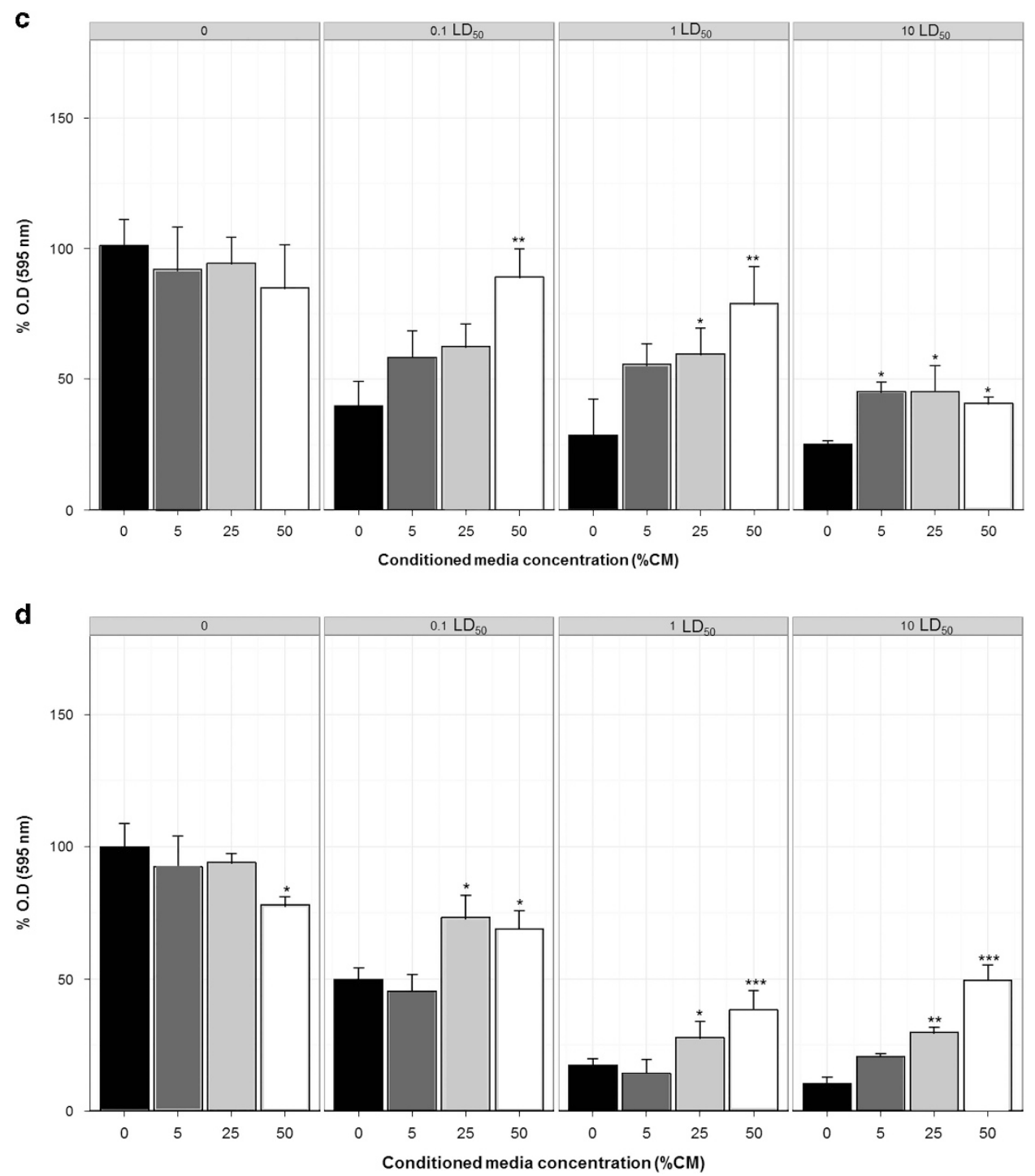

Figure 4 Continued

$\begin{array}{lllllllllll}M & A & \text { F } & \text { L } & \text { K } & \text { K } & S & \text { L } & \text { F } & \text { L }\end{array}$ GTGATTACTTTCCGAATTGCAAGAGCAGATATGGCTTTTTTGAAGAAATCACTTTTCCTT 60

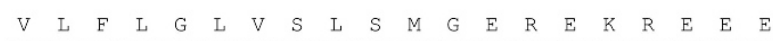
GTTCTATTCCTTGGATTAGTTTCCCTGTCCATGGGTGAAAGAGAGAAAAGAGAGGAAGAA 120

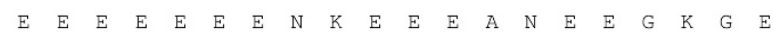
GAAGAAGAAGAAGAGGAAAACAAGGAAGAGGAAGCAAATGAAGAGGGAAAAGGGGAAAGT 180

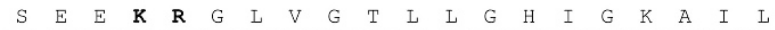
GAAGAAAAGAGAGGCCTGGTTGGCACATTATTAGGACACATTGGAAAAGCTATTCTTGGT 240 G $\quad$ *

GGCTAATTAAATGGTTCAGTTGTACTGAGCATTAATATTATTAGTTGTACTAGACATATA 300 TTAAAGCATATTTACCA----- 317

Figure 5 Skin micro-organs cDNA sequence from S. lacteus SI-11 clone encoding a novel peptide. The amino-acid sequence is given in single letters. Putative signal peptide sequence is single-underlined, acidic spacer domain is dotted-underlined, processing site K-R (lysine-arginine) is in bold letters, mature peptide sequence is bold-underlined and asterisk indicates stop codon.

It is important, however, to point out that activity of $\mathrm{F} 2.3 \mathrm{~S}$ was specific against YFV and had no toxic effect in the somatic cells tested as shown in Figure 7.

\section{F 2.3S MAFLKKSLFLVLELGLVSLSMGEREKREEEEEEEEENKEEEANEEGKGESEEKRGLVGTLLGHIGKAILGG

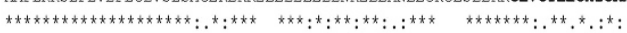 \\ F1.1 MAFLKKSLFLVLFLGLVSLSICEKEKK--EOEDEDENEEEKESEEG---SEEKRGLLDTLGGILGR}

Figure 6 Comparison of $S$. lacteus frenatin peptide ( $F$ 2.3S) with their close amphibian skin AMPs homolog, frenatin from Litoria genus (F 1.1). Peptide alignment is indicated as follow: $(*)$ conserved amino-acid residues, (:) amino-acid residues with similar properties, (.) amino-acid residues dissimilar and $(-)$ gaps.

Another important issue to evaluate in AMPs prospecting is the toxicity in somatic cells. Consequently, we determined the effect of the CMs from the seven frog species in CHO-K1 and Vero E6 cells at different $\mathrm{CM}$ dilutions. The results showed that just T. venulosus reduced the cell viability in CHO-K1 and Vero E6 (Figure 4d), but in both cases this reduction was not superior to $50 \%$. The other six-frog species' CMs were not cytotoxic for CHO-K1 (Figure 1) and Vero E6 (Figures 3 and 4). Additionally, we evaluated the cytotoxicity of F $2.3 \mathrm{~S}$ in Vero E6 cells and found that the peptide was not toxic at five times the concentration used in the antiviral assay. 
a

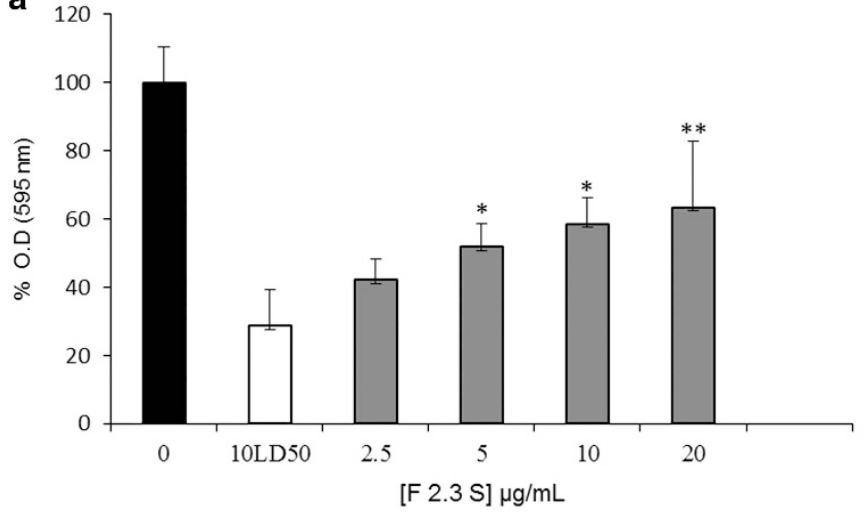

b

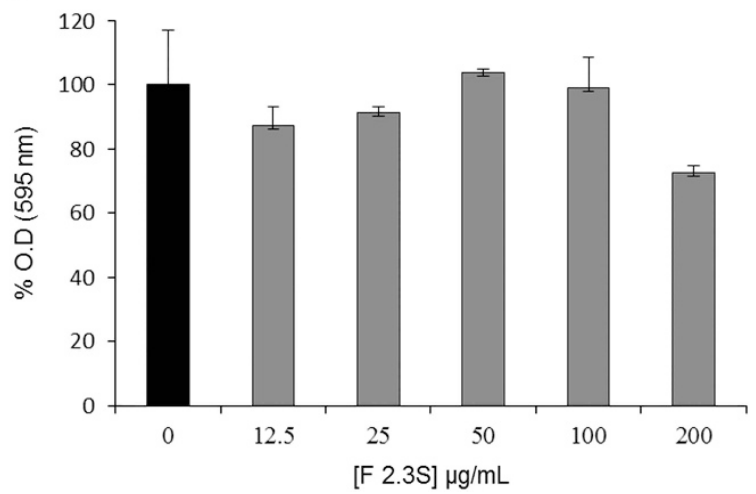

Figure 7 Antiviral (a) and cytotoxic (b) effect of $S$. lacteus frenatin $2.3 \mathrm{~S}$ peptide in Vero E6 cell line infected with YFV $(10$ LD 50$)$. Tukey * $P$-value $<0.05$, $* * P$-value $<0.01$

In summary, the results against YFV using CMs from different frog's species demonstrated the antiviral potential of these secretions, especially from S. lateus, C. boulengeri and L. fuscus. Therefore, it can be concluded that these CMs are good candidates for further proteomic and biological characterization. We have also identified encoding precursor for F $2.3 \mathrm{~S}$ peptide from $S$. lacteus SMOs, which may be a key component on facilitating the strong anti-YFV activity found in skin secretions of S. lacteus.

Activity of F $2.3 \mathrm{~S}$ was specific against YFV and had no toxic effect against the actual somatic cells tested. We have not tested the activity of F $2.3 \mathrm{~S}$ peptide against other viruses. However, it is rare that frogs would have developed a mechanism in which a single peptide either works alone or is toxic to only one type of micro-organism. In spite of this, it is surprising that F $2.3 \mathrm{~S}$ can display a 35\% YFV inhibition on its own. As shown here, total CM from S. lacteus has a much potent activity than the isolated peptide. Most probable-as discussed previously ${ }^{19}$-antimicrobial activity secreted by skin of amphibians is unlikely to be caused by a single peptide and it is the combinations of various of them that provide a broader and effective antimicrobial effect.

Accordingly with this, other authors demonstrated that AMPs individually have a certain spectra of antimicrobial activity, but their activity was considerably amplified upon combination with other peptides. ${ }^{35}$ In nature synergism within AMPs contributes to the explanation of the presence of several peptides in most tissues in different species, in order to broaden the antimicrobial spectrum AMPs. ${ }^{36}$

\section{CONFLICT OF INTEREST}

The authors declare no conflict of interest.

\section{ACKNOWLEDGEMENTS}

This research was funded by COLCIENCIAS CODE 1204-343, by Comité de Investigaciones y Postgrados, Facultad de Ciencias from Universidad de los Andes, Colombia, Fundación Bolivar Davivienda, Labbrands and by a special grant from the Hebrew University to E.M. We thank Dr Jhon Lynch, Universidad Nacional de Colombia, Dr Andrew Crawford and Dr Adolfo Amézquita, Universidad de los Andes for they kind help in the identification of the species collected Jairo Mendez, Instituto Nacional de Salud for his advice with the antiviral assays.
1 Waghu, F. H. et al. CAMP: collection of sequences and structures of antimicrobial peptides. Nucleic Acids Res. 42, 1154-1158 (2014).

2 Conlon, J. M. \& Mechkarska, M. Host-defense peptides with therapeutic potential from skin secretions of frogs from the family pipidae. Pharmaceuticals (Basel) 7, 58-77 (2014).

3 Vanhoye, D., Bruston, F., Nicolas, P. \& Amiche, M. Antimicrobial peptides from hylid and ranin frogs originated from a 150-million-year-old ancestral precursor with a conserved signal peptide but a hypermutable antimicrobial domain. Eur. J. Biochem. 270, 2068-2081 (2003)

4 Conlon, J. M. The contribution of skin antimicrobial peptides to the system of innate immunity in anurans. Cell Tissue Res. 343, 201-212 (2011).

5 Conlon, J. M. et al. A family of antimicrobial and immunomodulatory peptides related to the frenatins from skin secretions of the Orinoco lime frog Sphaenorhynchus lacteus (Hylidae). Peptides 56, 132-140 (2014).

6 Mechkarska, M. et al. An analog of the host-defense peptide hymenochirin-1B with potent broad-spectrum activity against multidrug-resistant bacteria and immunomodulatory properties. Peptides 50, 153-159 (2013).

7 Conlon, J. M. et al. Isolation of peptides of the brevinin-1 family with potent candidacidal activity from the skin secretions of the frog Rana boylii. J. Pept. Res. 62, 207-213 (2003).

8 Conlon, J. M. et al. Evaluation of the Skin Peptide Defenses of the Oregon Spotted Frog Rana pretiosa Against Infection by the Chytrid Fungus Batrachochytrium dendrobatidis. J. Chem. Ecol. 39, 797-805 (2013).

9 Bergaoui, I. et al. In vitro antiviral activity of dermaseptin S4 and derivatives from amphibian skin against herpes simplex virus type 2. J. Med. Virol. 85, 272-281 (2013).

10 Belaid, A. et al. In vitro antiviral activity of dermaseptins against herpes simplex virus type 1. J. Med. Virol. 66, 229-234 (2002).

11 Vancompernolle, S. E. et al. Antimicrobial peptides from amphibian skin potently inhibit human immunodeficiency virus infection and transfer of virus from dendritic cells to T cells. J. Virol. 79, 11598-11606 (2005).

12 Rushika, P., Mansoora, K. \& Richard, J. K. Closing the door on flaviviruses: entry as a target for antiviral drug design. Antiviral Res. 80, 11-22 (2009).

13 Umamaheswari, A., Kumar, M., Pradhan, D. \& Marisetty, H. Docking studies towards exploring antiviral compounds against envelope protein of yellow fever virus. Interdiscip. Sci. Comput. Life Sci. 3, 64-77 (2011).

14 Monath, T. P. Yellow fever: an update. Lancet Infect. Dis. 1, 11-20 (2015).

15 Staples, J. \& Monath, T. Yellow fever: 100 years of discovery. J. Am. Med. Assoc. 300, 960-962 (2008)

16 Mastrangelo, E. et al. Ivermectin is a potent inhibitor of flavivirus replication specifically targeting NS3 helicase activity: new prospects for an old drug. J. Antimicrob. Chemother. 67, 1884-1894 (2012).

17 Hill, D. Mapping the risk of yellow fever infection. Curr. Infect. Dis. Rep. 14, 246-255 (2012).

18 Ngoagouni, C. et al. Entomological profile of yellow fever epidemics in the Central African Republic, 2006-2010. Parasit. Vectors 5, 175 (2012).

19 Groot, H. et al. Skin micro-organs from several frog species secrete a repertoire of powerful antimicrobials in culture. J. Antibiot. 65, 461-467 (2012).

20 Rollins-Smith, L. A. et al. Activity of antimicrobial skin peptides from ranid frogs against Batrachochytrium dendrobatidis, the chytrid fungus associated with global amphibian declines. Dev. Comp. Immunol. 26, 471-479 (2002).

21 Chomczynski, P. \& Sacchi, N. Single-step method of RNA isolation by acid guanidinium thiocyanate-phenol-chloroform extraction. Anal. Biochem. 162, 156-159 (1987).

22 Chen, T., Zhou, M., Gagliardo, R., Walker, B. \& Shaw, C. Elements of the granular gland peptidome and transcriptome persist in air-dried skin of the South American orange-legged leaf frog, Phyllomedusa hypocondrialis. Peptides 27, 2129-2136 (2006). 
23 Altschul, S. F. et al. Gapped BLAST and PSI-BLAST: a new generation of protein database search programs. Nucleic Acids Res. 25, 3389-3402 (1997).

24 Thompson, J. D., Gibson, T. J. \& Higgins, D. G. Multiple Sequence Alignment Using ClustalW and ClustalX. Current Protocols in Bioinformatics. (John Wiley \& Sons, Inc., 2002).

25 Neyts, J., Meerbach, A., Mckenna, P. \& Declercq, E. Use of the yellow fever virus vaccine strain 17D for the study of strategies for the treatment of yellow fever virus infections. Antiviral Res. 30, 125-132 (1996).

26 Sudo, K., Konno, K., Yokota, T. \& Shigeta, S. A screening system for antiviral compounds against Herpes Simplex Virus type 1 using the MTT method with L929 cells. Tohoku J. Exp. Med. 176, 163-171 (1995).

27 Leyssen, P., De Clercq, E. \& Neyts, J. The anti-yellow fever virus activity of ribavirin is independent of error-prone replication. Mol. Pharmacol. 69, 1461-1467 (2006).

28 Zhou, M., Chen, T., Walker, B. \& Shaw, C. Novel frenatins from the skin of the Australasian giant white-lipped tree frog, Litoria infrafrenata: cloning of precursor cDNAs and identification in defensive skin secretion. Peptides 26, 2445-2451 (2005).

29 Clarke, B. T. The natural history of amphibian skin secretions, their normal functioning and potential medical applications. Biol. Rev. Camb. Philos. Soc. 72, 365-379 (1997).
30 Conlon, J. M. et al. An immunomodulatory peptide related to frenatin 2 from skin secretions of the Tyrrhenian painted frog Discoglossus sardus (Alytidae). Peptides 40, 65-71 (2013).

31 Chinchar, V. G. et al. Inactivation of viruses infecting ectothermic animals by amphibian and piscine antimicrobial peptides. Virology 323, 268-275 (2004).

32 Albiol Matanic, V. \& Castilla, V. Antiviral activity of antimicrobial cationic peptides against Junin virus and herpes simplex virus. J. Antimicrob. Agents 23, 382-389 (2004).

33 Davies, J. \& Davies, D. Origins and evolution of antibiotic resistance. Microbiol. Mol. Biol. Rev. 74, 417-433 (2010).

34 Klotman, M. E. \& Chang, T. L. Defensins in innate antiviral immunity. Nat. Rev. Immunol. 6, 447-456 (2006).

35 Mor, A., Hani, K. \& Nicolas, P. The vertebrate peptide antibiotics dermaseptins have overlapping structural features but target specific microorganisms. J. Biol. Chem. 269, 31635-31641 (1994).

36 Cassone, M. \& Otvos, L. Synergy among antibacterial peptides and between peptides and small-molecule antibiotics. Expert Rev. Anti. Infect. Ther. 8, 703-716 (2010). 